\title{
New X-ray Transparent and Light Tight Windows for EDS Detectors
}

\author{
M.Bornschlegl $^{1}$, A.Niculae ${ }^{1}$, H.Soltau ${ }^{1}$, R.Eckhardt ${ }^{1}$, K.Hermenau ${ }^{1}$ \\ ${ }^{1}$ PNDetector GmbH, Emil-Nolde-Str.10, 81735 Munich, Germany
}

High reliability X-ray transmission windows are important components of radiation detector modules used in X-ray spectroscopy. They have to give protection against environmental influences, like moisture and chemicals, or optical light, and at the same time good transmission for the X-ray energies of interest is required.

There are various window types available - such with high quantum efficiency at all energies, windows with optical light suppressing properties and such with maximum light shielding for laboratory and TEM applications or XRF handheld equipment. Commonly, ultra thin Polymide windows or Beryllium windows have been used within this field over years. Recently we developed a new type of transparent detector windows realized on a silicon frame in a planar process and consisting of one or more dielectric and metal layers. These thin windows are called Planar Thin Windows (PTWs) due to the way they have been processed. They are available in different forms, sizes (see Fig.1) and modifications. The properties of the windows can be tailored for the specific application requirements: There are transparent windows with no light shielding and optimized performance for standard SEM applications and there is a new type of Planar Thin Window with good light shielding properties but though enhanced low energy quantum efficiency called Planar Thin Window Plus (PTW ${ }^{\text {plus }}$ ).

Windows up to $10 \mathrm{~mm}^{2}$ active area do not require a supporting grid, therefore offering maximum X-ray transmission (see Fig.1a and Fig.2). For larger area detectors (30, 60, 100, $300 \mathrm{~mm}^{2}$ ) a grid is necessary for mechanical stability (see Fig.1b,c). Based on the high clearance of the grid, the window transmission is not reduced by more than $20 \%$. The mechanical stability independence of the window dimensions will be demonstrated. In addition the windows are tested intensively for vacuum tightness and resistance against environmental influence as e.g. moisture, temperature, mechanical stress and light. We report on those and further measurement results.

Fig.2 shows the X-ray transmission curves of a transparent PTW, a light suppressing PTW ${ }^{\text {plus }}$-LS and a common polymere window (AP3.3, www.moxtek.com) demonstrating superior transmission for PTWs for X-rays above $300 \mathrm{eV}$. The values are once again summarized in Table 1 . The light attenuation of the light suppressing PTW ${ }^{\text {plus }}$-LS is $98 \%$, what makes it usuable for ambients with stray light.

Fig.3 shows the X-ray transmission of a light tight PTW ${ }^{\text {plus }}$-LT in comparison to a Beryllium window with a thickness of $12 \mu \mathrm{m}$. The light attenuation of the light tight PTW ${ }^{\text {plus }}$-LT is up to $10^{-7}$, i.e. comparable to Beryllium, allowing for the first time measurements of Carbon and Boron under daylight conditions. 


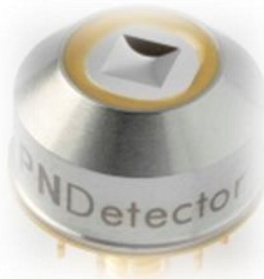

(a)

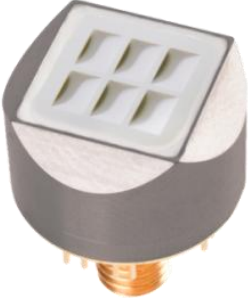

(b)

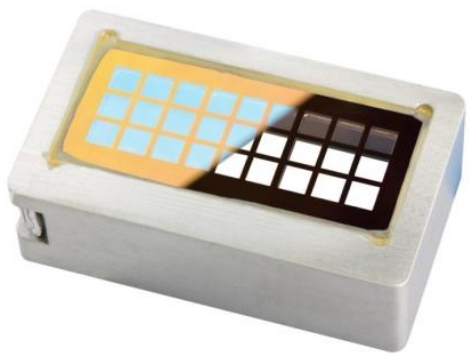

(c)

Fig. 1 (a) Light tight window PTW ${ }^{\text {plus }}$ LT without supporting grid for a SDD module with 10 $\mathrm{mm}^{2}$ active area; (b) light tight window PTW ${ }^{\text {plus }}$-LT mounted on a $100 \mathrm{~mm}^{2}$ module; (c) transparent window PTW-TP mounted on a $3 \times 100 \mathrm{~mm}^{2}$ module with supporting

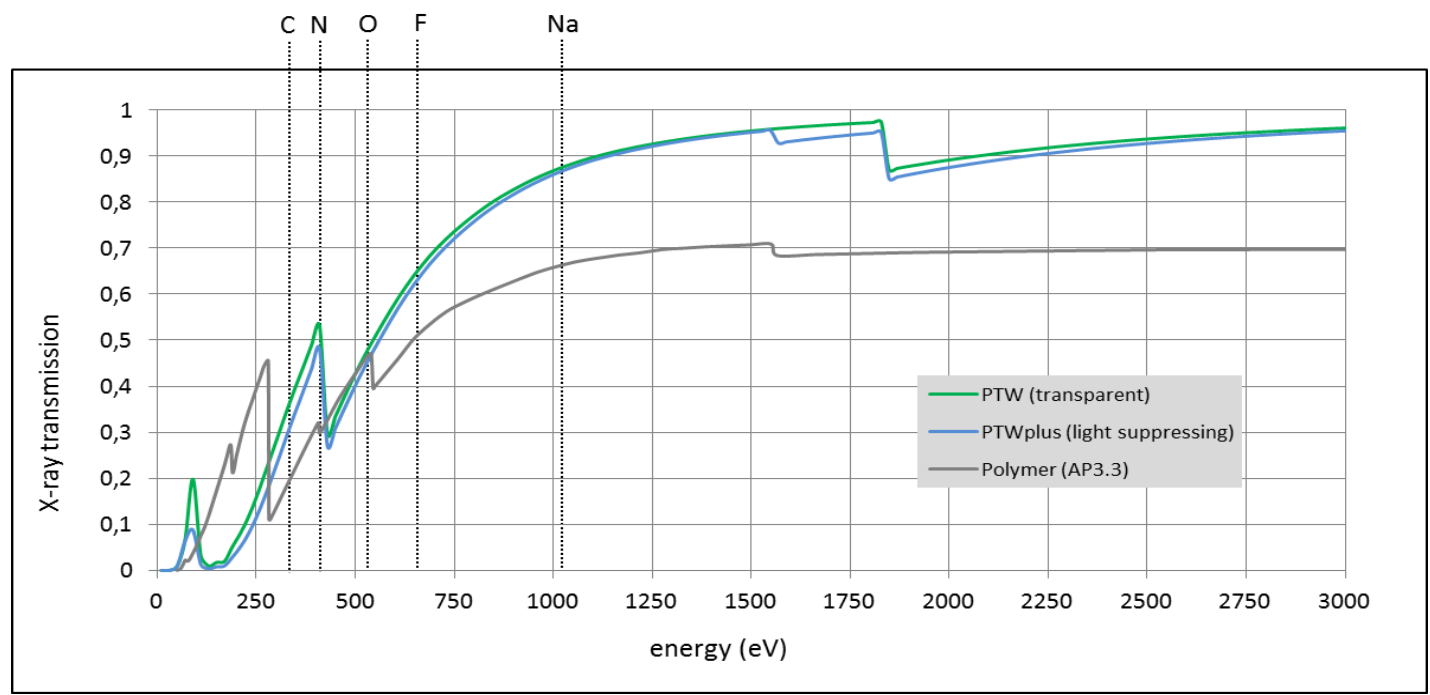

Fig. 2 X-ray transmission of windows for detectors with an active area of $10 \mathrm{~mm}^{2}$ : dedicated for SEM applications: PTW-TP, PTW ${ }^{\text {plus }}$-LS and AP3.3 (Polymere).

\begin{tabular}{|c|c|c|c|c|}
\hline $\begin{array}{c}\text { Element } \\
\text { (Energy) }\end{array}$ & \multicolumn{4}{|c|}{ X-Ray Transm ission } \\
\hline & PTW-TP & PTW $^{\text {plus }-L S ~}$ & PTW & \\
\hline $\begin{array}{c}\mathbf{C} \\
(277 \mathrm{eV})\end{array}$ & $23 \%$ & $18 \%$ & $9 \%$ & $\begin{array}{c}\text { Polymere } \\
\text { AP3.3 }\end{array}$ \\
\hline $\begin{array}{c}\mathbf{N} \\
(392 \mathrm{eV})\end{array}$ & $50 \%$ & $44 \%$ & $35 \%$ & $31 \%$ \\
\hline $\begin{array}{c}\mathbf{O} \\
(525 \mathrm{eV})\end{array}$ & $47 \%$ & $45 \%$ & $40 \%$ & $47 \%$ \\
\hline $\begin{array}{c}\mathbf{F} \\
(677 \mathrm{eV})\end{array}$ & $67 \%$ & $65 \%$ & $63 \%$ & $54 \%$ \\
\hline $\begin{array}{c}\mathbf{N a} \\
(1.04 \mathrm{keV})\end{array}$ & $88 \%$ & $87 \%$ & $86 \%$ & $69 \%$ \\
\hline
\end{tabular}

Tab. 1 X-ray transmission values in comparison

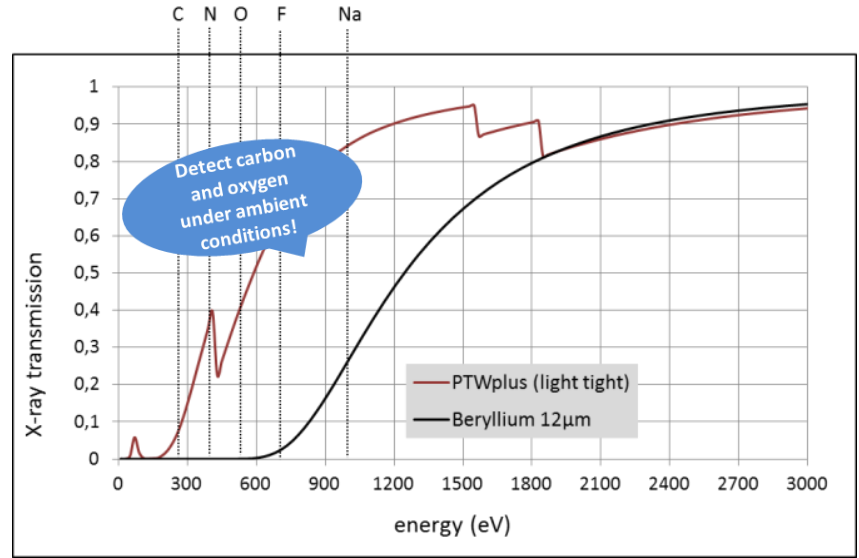

Fig. 3 X-ray transmission of light tight windows dedicated for detectors with an active area of 10 $\mathrm{mm}^{2}$ for XRF applications: PTW ${ }^{\text {plus }}-\mathrm{LT}$ and $12 \mu \mathrm{m}$ Beryllium. 